\title{
Impacts of the SSSC on Damping Power System Oscillations
}

\author{
Majid Dehghani ${ }^{1}$, Mehdi Mahdavian ${ }^{2}$ \\ ${ }^{I}$ Department of Electrical Engineering, Najafabad Branch, Islamic Azad University, Najafabad, Iran \\ ${ }^{2}$ Department of Electrical Engineering, Naein Branch, Islamic Azad University, Naein, Isfahan, Iran
}

*Corresponding Author: Majid Dehghani, Department of Electrical Engineering, Najafabad Branch, Islamic Azad University, Najafabad, Iran

\begin{abstract}
The planning and operation condition of electrical power systems are changing due to a variety of causes. FACTS controller helps in raising dynamic stability limit and provide better power flow control. Static synchronous series compensator (SSSC) is one of the important members of series FACTS controller, which consists of a solid-state voltage source inverter coupled with a transformer that is connected in series with a transmission line. In this paper is presented the effect of SSSC for damping power system oscillation. The complete digital simulation is performed in the Matlab Simulink environment.
\end{abstract}

Keywords: Oscillation damping; FACTS controller; SSSC

\section{INTRODUCTION}

From the steady-state point of view, FACTS devices operate by increasing or reducing voltage, supplying or absorbing reactive power and controlling the series impedance of transmission lines or phase angle [1-4]. FACTS controller can be classified in four main categories [5-7]: shunt controller, series controller, series-series controller and series-shunt controller [8-10]. A systematic classification of the FACTS devices is presented in Fig. 1 [11].

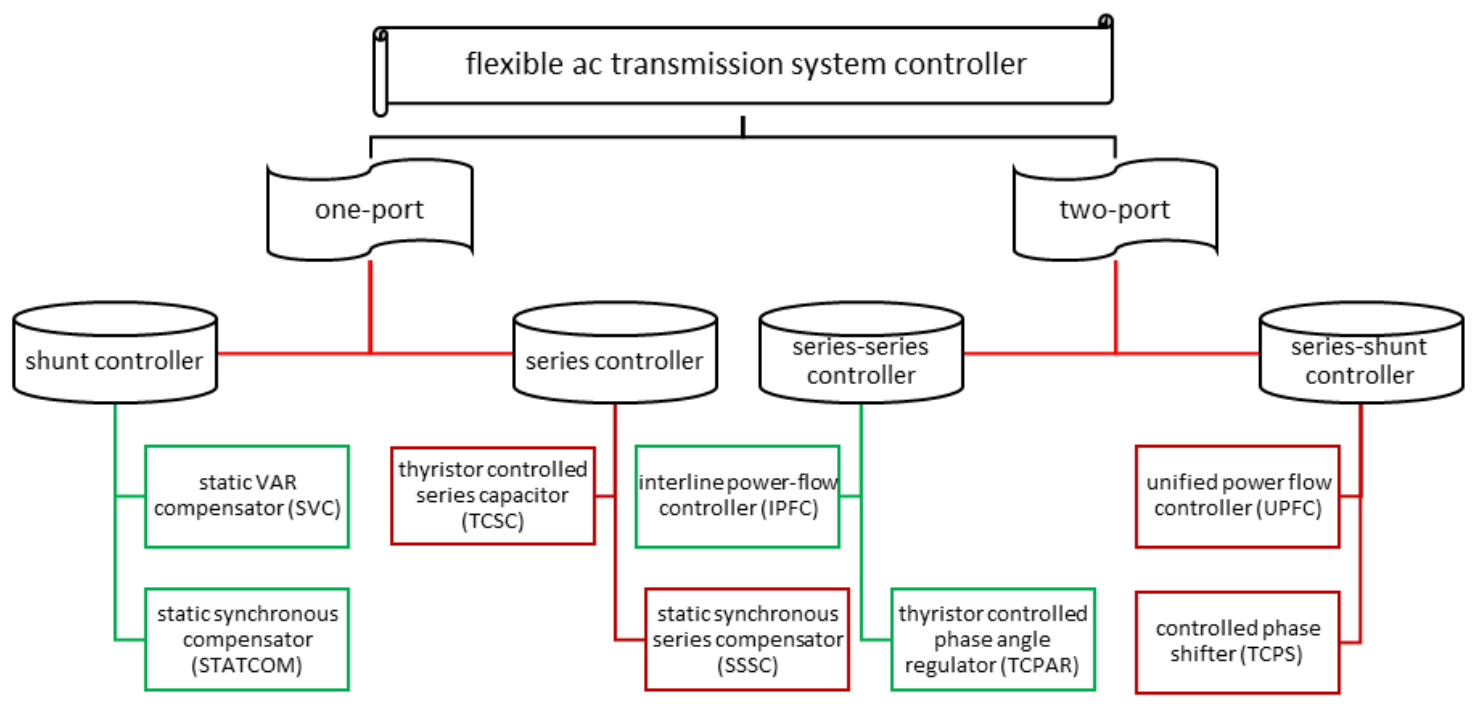

Fig1. Classification of the FACTS controller

In recent years, flexible ac transmission system (FACTS) devices equipped with a power oscillation damper (POD) have been also efficiently used for damping oscillations of power system [12-19]. Generally, there are two kinds of power oscillation damping controllers in power systems: power system stabilizer (PSS) [20-24] and FACTS POD controllers [25-28].

A method for designing of power system stabilizer (PSS) (lead-lag compensation type) based on sliding mode control technique is presented in [29], which the control objective is to enhance stability and improve the dynamic response of the multi-machine power system and, also, the main approach is 
to focus on the control performance which later is proven to have the degree of shorter reaching time and lower spike. For damping oscillations and to enhance the transient stability performance of power systems in [30] the UPFC is used, that the controller parameters are designed using an efficient version of the Takagi-Sugeno fuzzy control scheme. A design procedure for simultaneous coordinated designing of the static synchronous compensator controller parameters (STATCOM) and PSS in multi-machine power system is developed in [31], that the artificial bee colony algorithm is employed to search for optimal controller's parameters. To set the parameters of FACTS devices, genetics and particle swarm optimization with fuzzy logic techniques have been used in [32], which to optimize the reactive power consumption and reduce the line congestion, two types of FACTS devices; thyristor controlled series compensator (TCSC) and static var compensator (SVC), are used. To verify the capability of the distributed SSC as a member of DFACTS family in mitigating the sub-synchronous resonance is purposed in [33], that two controllers the particle swarm optimization-based conventional damping controller and the fuzzy logic based damping controller are designed and implemented in traditional controller of the distributed SSC in order to provide the effective damping. A multiobjective approach for daily scheduling of microgrids contributing to a higher penetration of photovoltaics is studied in [34], which the existing control devices including DSTATCOM and underload tap changer are integrated in volt/var control process.

Static synchronous series compensator (SSSC) is one of the important members of FACTS family. It is able to providing the reactive power compensation of power system. Several references in technical literature can be found on the application of SSSC for power oscillation damping $[35,36]$ and stability improvement in power system [37].

Power system stability enhancement via robust coordinated design based on an optimization problem with a time-domain simulation-based objective function and real-coded genetic algorithm of a PSS and a SSSC-based controller is show in [38]. A control scheme to damp the low-frequency oscillations and voltage deviations of a multi-machine power system using an ant colony optimization-based static synchronous compensator is developed in [39], which the control scheme incorporates two different proportional-integral controllers to control the gate signal in the SSC and, also, the time-domain results of the rotor dynamics and deviation in generator voltage for various test cases reveal the potential of the proposed controller in in alleviating the overall power system oscillations. The stability improvement and power-flow control results of a DFIG-based offshore wind farm connected to a one-machine infinite-bus system using a SSSC is presented in [40], which an oscillation damping controller is designed by using modal control theory. The sub-synchronous resonance characteristics of the hybrid series compensation using SSSC and passive series capacitor discussed in [41] and proposes a method for the extraction of sub-synchronous components of line current using filter. A hybrid firefly algorithm and pattern search technique for a SSSC-based power oscillation damping controller design is proposed in [42], which a modified signal equivalent to the remote speed deviation signal is constructed from the local measurements. The stability issues of the double fed induction generator based wind farm in the power system with variable wind speed in strong and weak grid is studied in [43], which the impact of PSS and SSSC on the stability of wind power system is analyzed by utilizing modified IEEE 14-bus test system.

The SSSC is an important device to control transmission line impedance, and so to power flow control independent of the line current. In this paper, the application of SSSC in damping power system oscillation is investigated. Matlab Simulink software package is used for the simulations.

\section{STATIC SYNCHRONOUS SERIES COMPENSATOR}

SSSC is a series connected FACTS devices which can be installed in series in the transmission lines. It is very effective in controlling power flow in a transmission line with the capability to change its reactance characteristic from capacitive to inductive [44]. When the SSSC operates in inductive mode, the injected voltage is leading the line current and therefore reactive power is absorbed. In capacitive mode, the injected voltage is lagging the line current and therefore reactive power is injected into the transmission line. The SSSC injects a series ac voltage to transmission line through a transformer as shown in Fig. 2. 


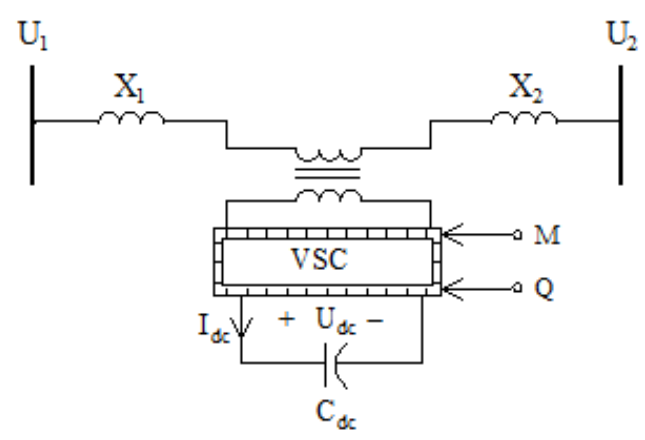

Fig2. Power system with SSSC

$\mathrm{U}_{1}$ and $\mathrm{U}_{2}$ are the bus voltages and $\mathrm{U}_{\mathrm{dc}}$ is the dc voltage source. $\mathrm{X}_{1}$ represents the equivalent reactance between the bus 1 and the SSSC, and $\mathrm{X}_{2}$ represents the equivalent reactance between SSSC and the bus 2 . The converter voltage is varied by changing the $\mathrm{M}$ is the amplitude modulation ratio and $\phi$ is the phase angle modulation ratio. A capacitor connected on the dc side of the VSC acts as a dc voltage source. The SSSC output voltage is defined by the following equation [45]:

$\mathrm{U}_{\mathrm{S}}=\mathrm{MU}_{\mathrm{dc}}(\cos \phi+\mathrm{j} \sin \phi)$

The differential equation of the dc voltage is given below:

$\frac{\mathrm{d} \mathrm{U}_{\mathrm{dc}}}{\mathrm{dt}}=\frac{\mathrm{M}}{\mathrm{C}_{\mathrm{dc}}}\left(\mathrm{i}_{\mathrm{q}} \cos \varphi+\mathrm{i}_{\mathrm{d}} \sin \varphi\right)$

where $i_{d}$ and $i_{q}$ are the $d$ and $q$ axes currents of transmission line. The structure of SSSC-based controller is shown in Fig. 3. The input signal of the proposed controller is the rotor angle deviation $(\Delta \delta)$ and the output signal is the injected voltage Vs. The structure consists of a gain block with gain $\mathrm{K}_{\mathrm{P}}$, a signal washout block with the time constant $\mathrm{T}_{\mathrm{W}}$ and two-stage phase compensation blocks.

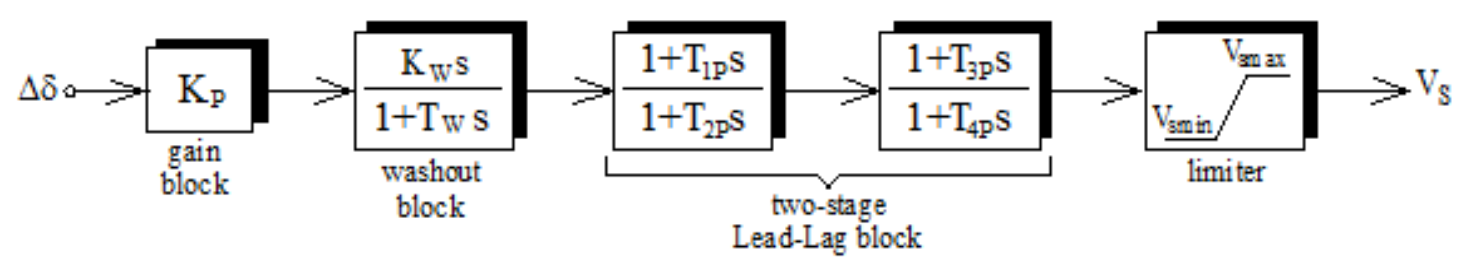

Fig3. Structure of SSSC-based controller

\section{SYSTEM UNDER STUDY}

The simulation bock diagram of the power system with a SSSC in Matlab/Simulink environment is shown in Fig. 4. The power grid consists of two power generation substations and one major load center at bus B3. The load center is modeled using a dynamic load model where the active and reactive power absorbed by the load is a function of the system voltage. Line L2 is split in two segments in order to simulate a three-phase fault at the midpoint of the line. The active power and reactive power measured at bus are shown in Figs. 5 and 6. When the SSSC is bypass, the power flow towards major load is as follows: $664 \mathrm{MW}$ flow on L1, $563 \mathrm{MW}$ flow on L2 and $990 \mathrm{MW}$ flow on L3. There are measured at bus B2, B4 and B3, respectively. The SSSC, located at bus B1, is in series with line L1. It is capable of injecting up to $10 \%$ of the nominal system voltage. The SSSC injected voltage reference is normally set by a POD controller whose output is connected to the $\mathrm{U}_{\mathrm{q}}$ input of the SSSC. The inputs to the POD controller are the bus voltage at B2 and the current flowing in L1.

\section{Simulation ReSUlts}

The initially of the input of the POD controller (reference voltage $U_{q}$ ) is zero. At $t=2 \mathrm{~s}, \mathrm{U}_{\mathrm{q}}$ is $-0.08 \mathrm{pu}$ (SSSC inductive) and at $\mathrm{t}=6 \mathrm{~s}, \mathrm{U}_{\mathrm{q}}$ is $0.08 \mathrm{pu}$ (SSSC capacitive). The active power flow on line $\mathrm{L} 1$, measured at bus B2, is show in Fig. 7. Depending on the injected voltage, the power flow on line varies from 575 to $750 \mathrm{MW}$. A comparison of the SSSC operation with and without POD control is shoe in Fig. 8. Therefore, the SSSC with a POD controller is a very effective tool to damp power 
oscillation. The output active power of the machine M1 for two cases are shown in Figs. 9 and 10. Also the rotor speed are shown in Figs. 11 and 12, and the excitaion voltage are shown in Figs. 13 and 14 for two cases of machine M1.

\section{CONCLUSION}

Damped oscillations are contributing an important role in power system. The effect of SSSC for damping power system oscillation is presented. This work is carried out under Matlab environment using Simulink and PSB toolboxes. The simulation results show that the SSSC controller is efficient in damping power oscillations.

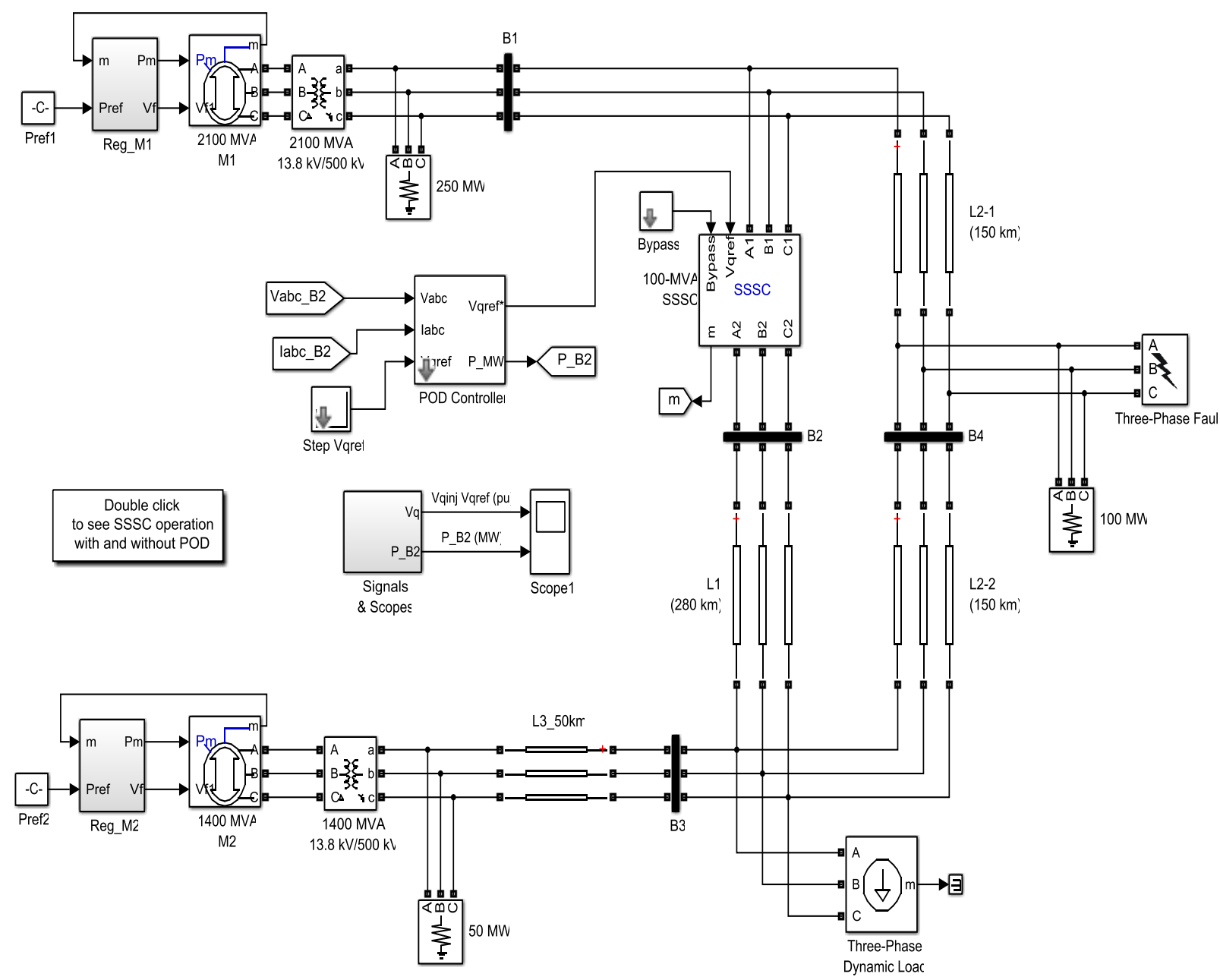

Fig4. Simulation block diagram of the power system with a SSSC in Matlab/Simulink

Table1. System Parameters

\begin{tabular}{|c|c|}
\hline Components & Value \\
\hline SSSC & $\begin{array}{c}\mathrm{S}_{\mathrm{n}}=100 \mathrm{MVA}, \mathrm{U}_{\mathrm{dc}}=40 \mathrm{KV} \\
\mathrm{Cdc}=375 \mu \mathrm{F}, \mathrm{X}_{\mathrm{eq}}=0.16 \mathrm{pu}\end{array}$ \\
\hline $\begin{array}{c}\text { power generation } \\
\text { substation (M1) }\end{array}$ & $6 \times 350 \mathrm{MW}$ \\
\hline $\begin{array}{c}\text { power generation } \\
\text { substation (M2) }\end{array}$ & $4 \times 350 \mathrm{MW}$ \\
\hline load center & $2200 \mathrm{MW}$ \\
\hline line $\mathrm{L}_{1}$ & $280 \mathrm{Km}$ \\
\hline line $\mathrm{L}_{2}$ & $300 \mathrm{Km}$ \\
\hline line $\mathrm{L}_{3}$ & $50 \mathrm{Km}$ \\
\hline POD & $\mathrm{K}_{\mathrm{P}}=0.08, \mathrm{~T}_{\mathrm{W}}=1 \mathrm{~s}, \mathrm{~K}_{\mathrm{W}}=1, \mathrm{~T}_{\mathrm{P} 1}=1 \mathrm{~s}, \mathrm{~T}_{\mathrm{P} 2}=0.1 \mathrm{~s}, \mathrm{~V}_{\mathrm{smin}}=-0.1, \mathrm{~V}_{\mathrm{smax}}=0.1$ \\
\hline
\end{tabular}




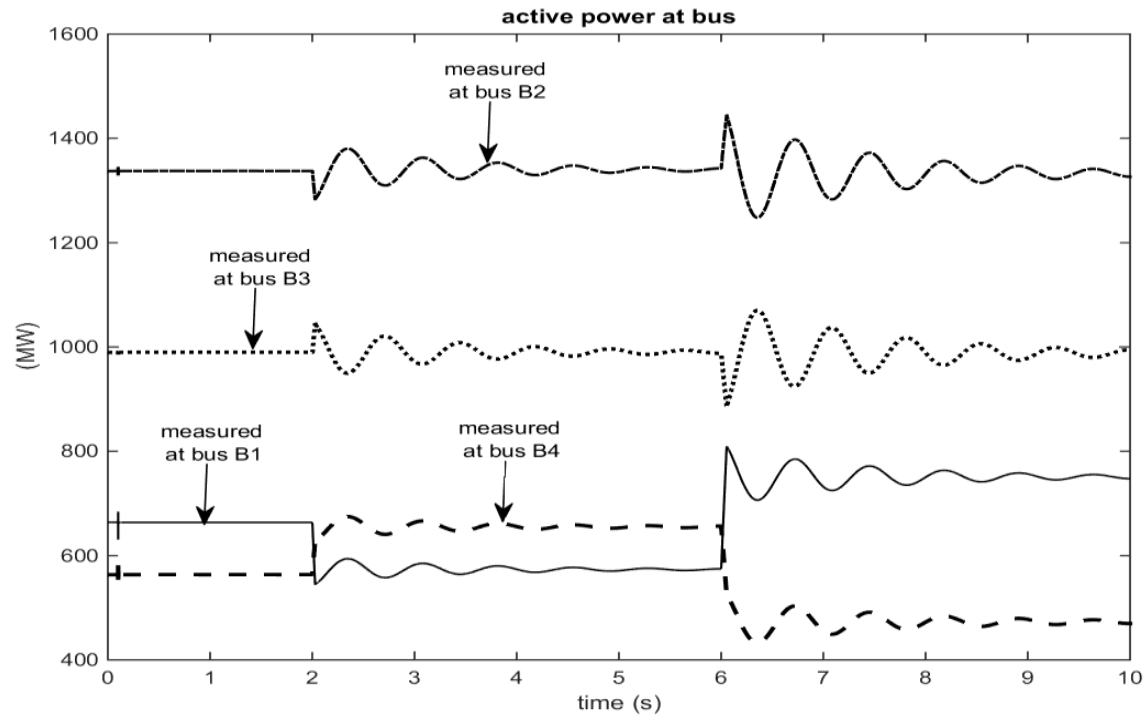

Fig5. Active power measured at bus

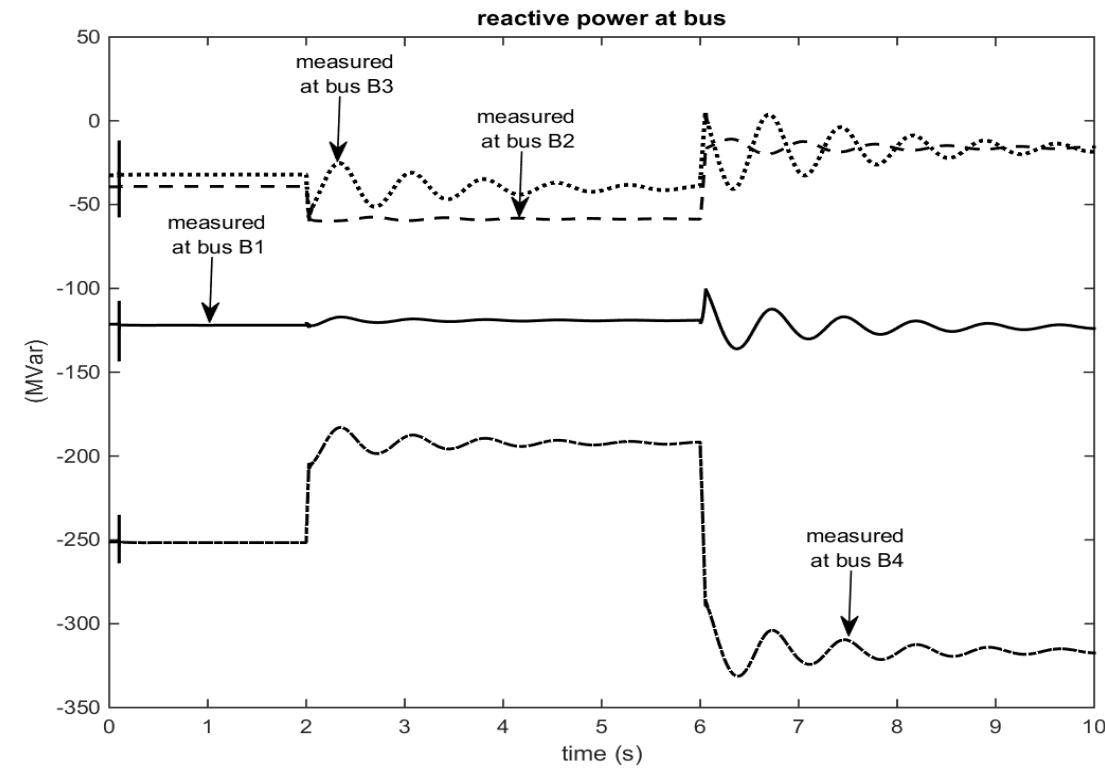

Fig6. Reactive power measured at buses

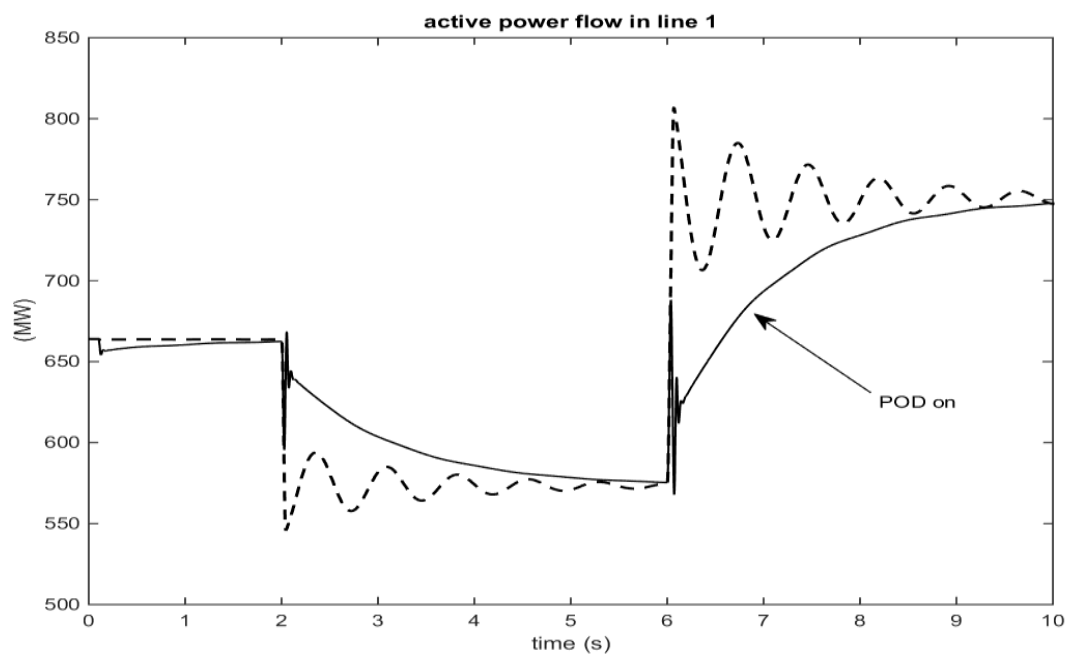

Fig7. Active power flow on line 1 that the SSSC operation with and without POD 


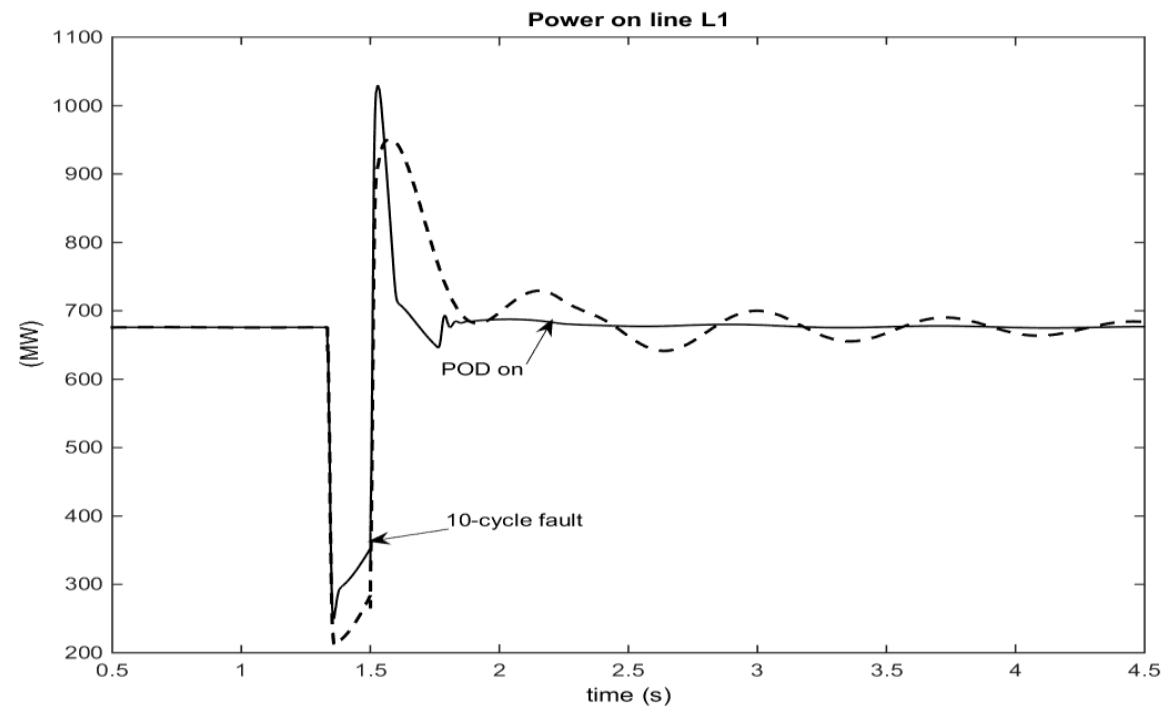

Fig8. Power on line 1 that the SSSC operation with and without POD

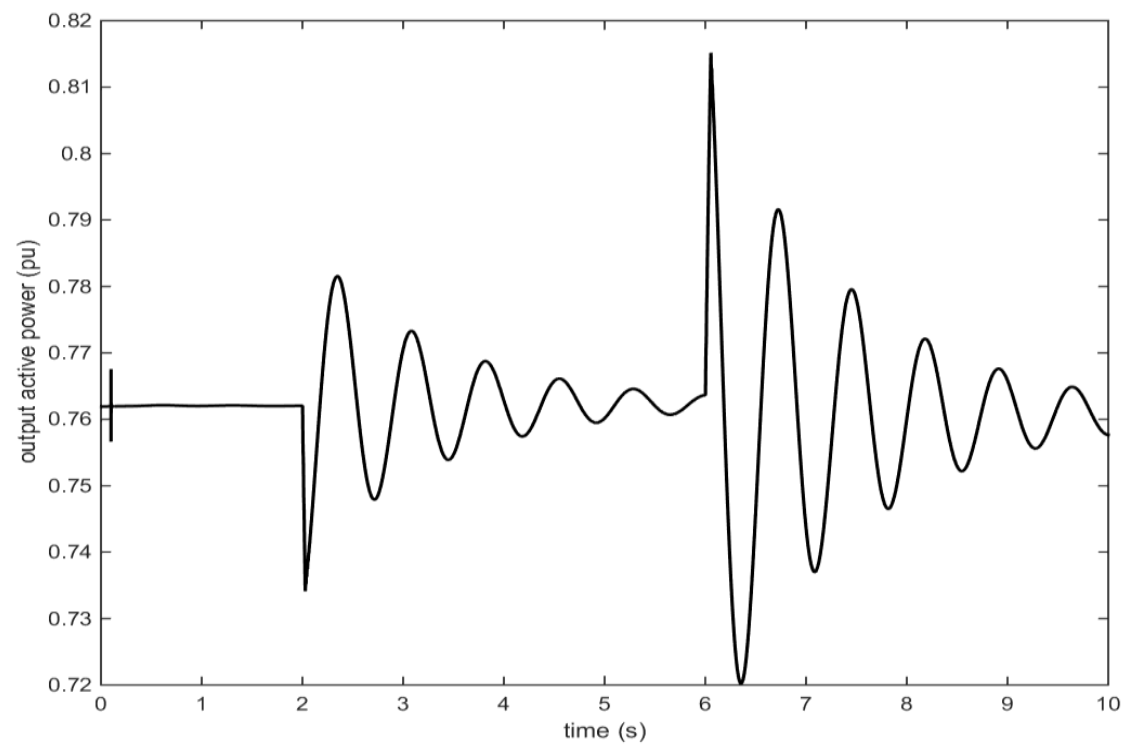

Fig9. Output active power without $P O D$

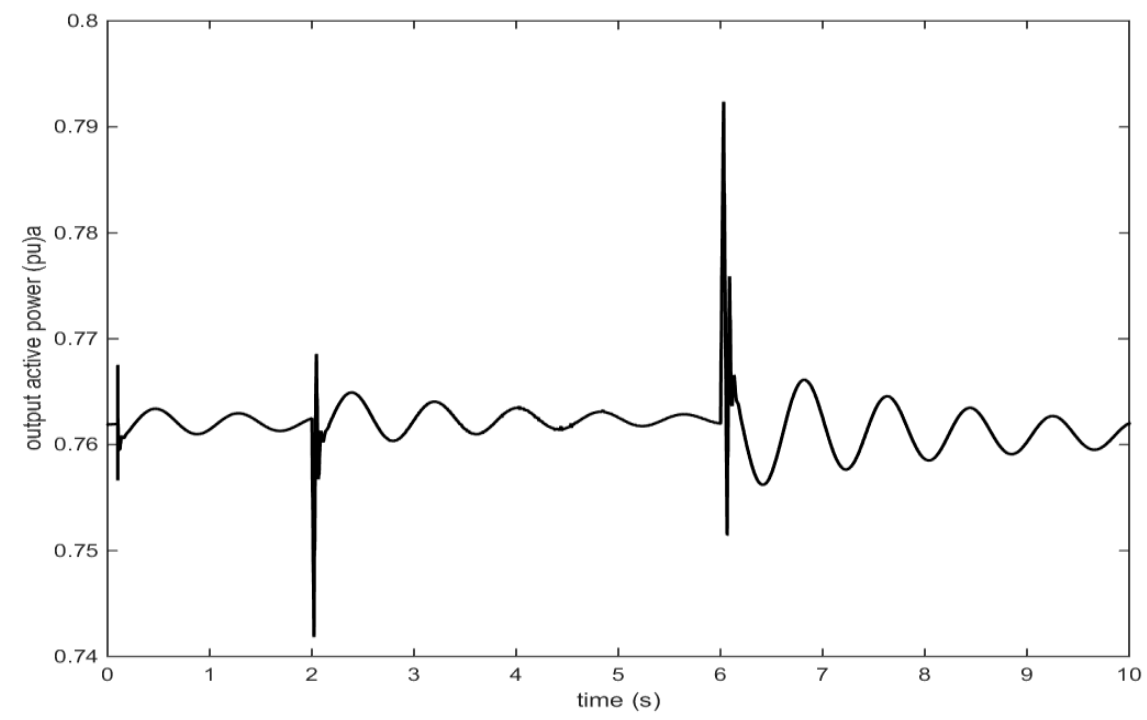

Fig10. Output active power without POD 


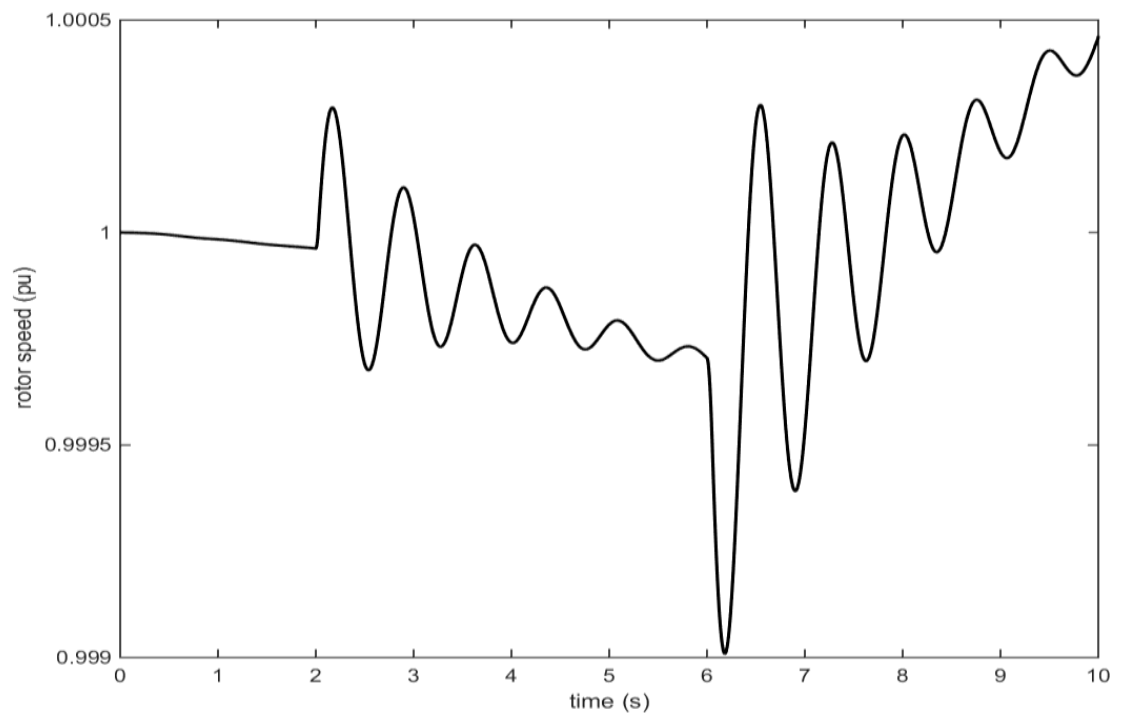

Fig11. Rotor speed without POD

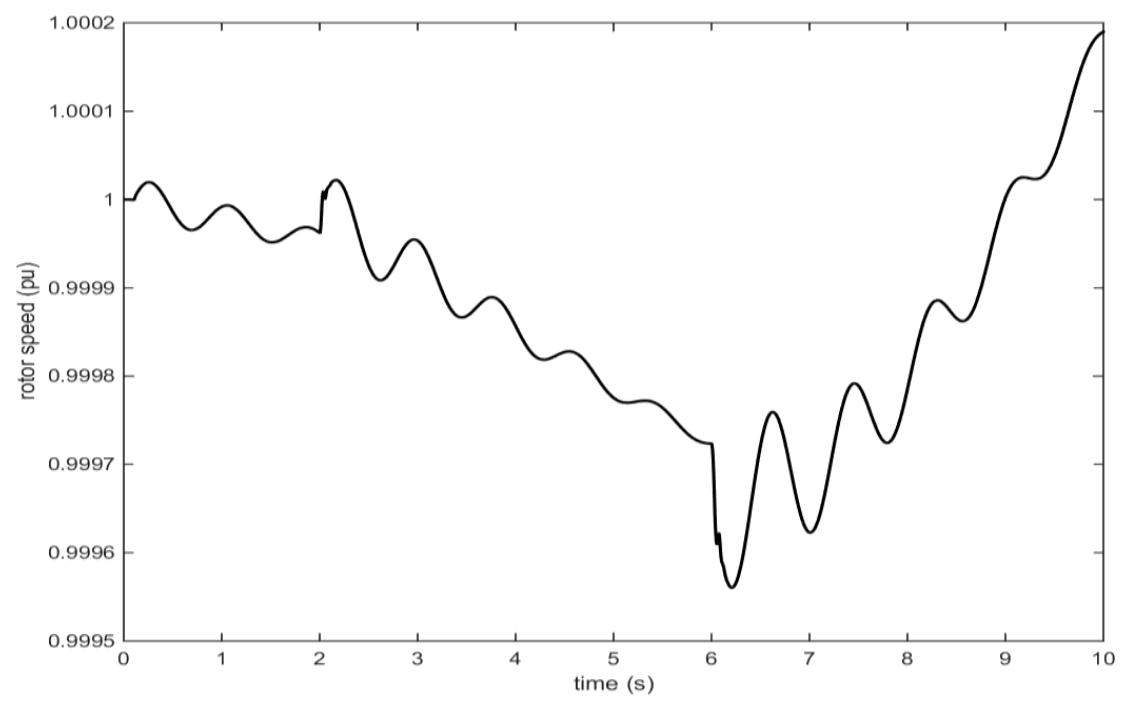

Fig12. Rotor speed without POD

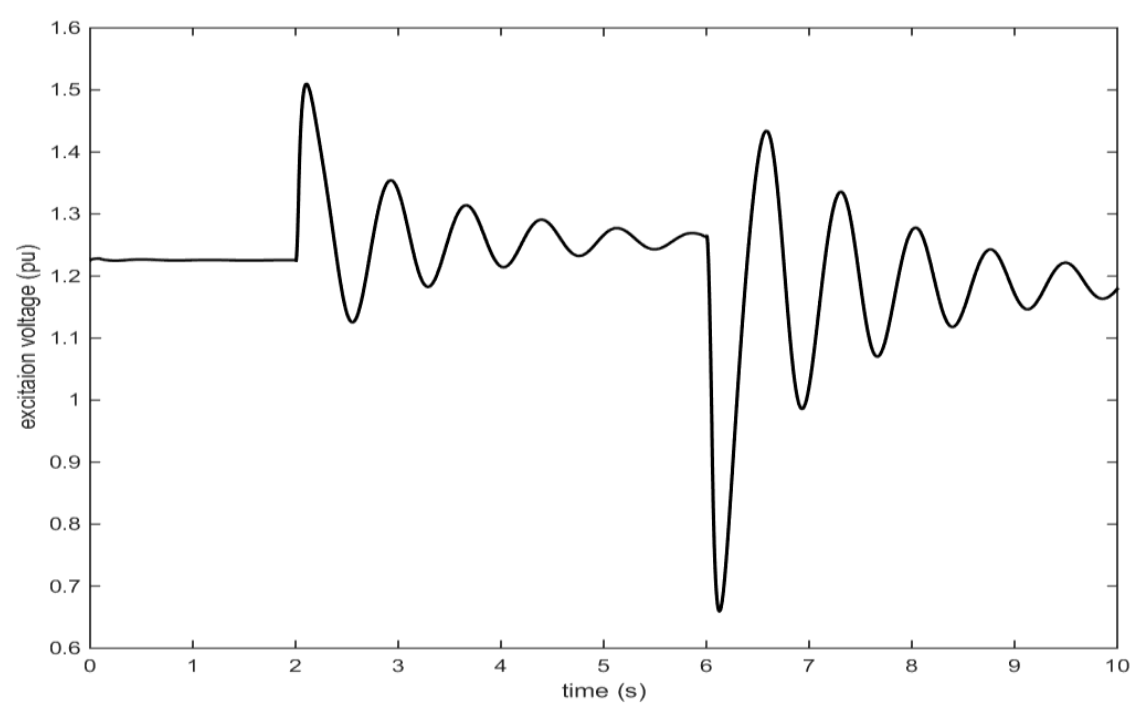

Fig13. Excitaion voltage without $P O D$ 


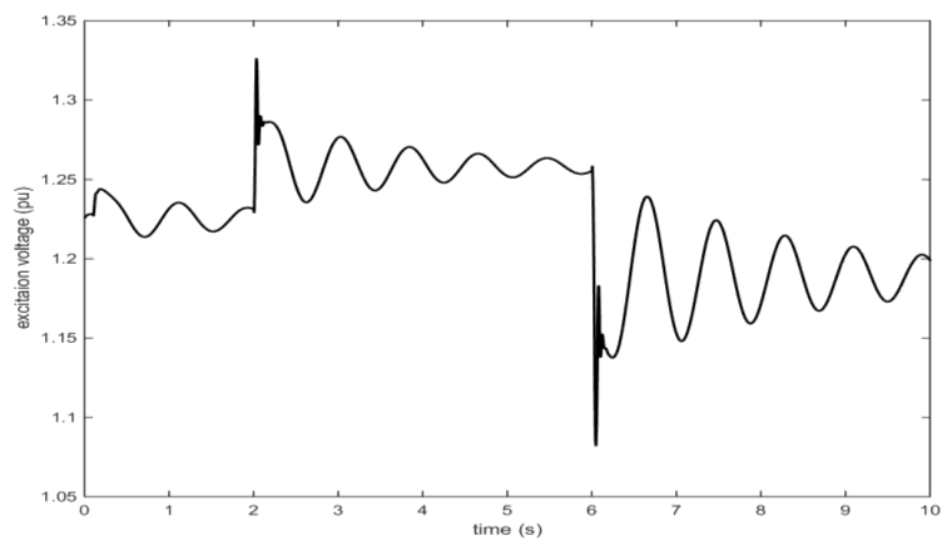

Fig14. Excitaion voltage with $P O D$

\section{REFERENCES}

[1] Z. Azimi, G. Shahgholian, "Power system transient stability enhancement with TCSC controller using genetic algorithm optimization", International Journal of Natural and Engineering Sciences, Vol. 10, No. 3, pp. 9-14, 2016.

[2] G. Shahgholian, N. Izadpanahi, "Improving the performance of wind turbine equipped with DFIG using STATCOM based on input-output feedback linearization controller", Energy Equipment and Systems, Vol. 4, No. 1, pp. 65-79, June 2016.

[3] G. Shahgholian, E. Haghjoo, A. Seifi, I. Hassanzadeh, "The improvement DSTATCOM to enhance the quality of power using fuzzy-neural controller", Journal of Intelligent Procedures in Electrical Technology, Vol. 2, No. 6, pp. 3-16, Summer 2011.

[4] F. Mogharrab-Tehrani, G. Shahgholian, H. Pourghassem, "Dynamic study and stability analyze of damping cohefision and reactance in TCSC controller connected on optimization SMIB system", Proceeding of the IEEE/ ICCSN, pp. 270-274, China, May 2011.

[5] G. Shahgholian, J. Faiz, "Coordinated control of power system stabilizer and FACTS devices for dynamic performance enhancement- State of art", Proceeding of the IEEE/IEPS, pp. 1-6, Kyiv, Ukraine, June 2016.

[6] P. Bhatt, S.P. Ghoshal, R. Roy, "Load frequency stabilization by coordinated control of thyristorcontrolled phase shifters and superconducting magnetic energy storage for three types of interconnected two-area power systems", International Journal of Electrical Power and Energy Systems, vol. 32, pp. $1111-1124,2010$.

[7] G. Shahgholian, P. Shafaghi, S. Moalem, M. Mahdavian, "Damping power system oscillations in singlemachine infinite-bus power system using a STATCOM", Proceeding of the IEEE/ICCEE, pp.130-134, Dubai, Dec. 2009.

[8] G. Shahgholian, B. Bayat, "A new control technique for improving the oscillations and decreasing the harmonic components of voltage in STATCOM", International Review of Electrical Engineering, Vol. 6, No. 6, pp. 3163-3174, 2011.

[9] A. Motaghi, M. AaLIzadeh, M. Abbasian, "Reactive power compensation and reducing network transmission losses by optimal placement of parallel and series FACTS devices with fuzzy-evolutionary method", Journal of Intelligent Procedures in Electrical Technology, vol. 9, no. 35, pp. 27-38, Autumn 2019.

[10] G. Shahgholian, J. Faiz, "Static synchronous compensator for improving performance of power system: A review", International Review of Electrical Engineering, Vol. 4, No. 2, pp. 2333-2342, Oct. 2010.

[11] G. Shahgholian, "Development of state space model and control of the STATCOM for improvement of damping in a single-machine infinite-bus", International Review of Electrical Engineering, Vol.4, No.6, pp.1367-1375, Nov./Dec. 2009.

[12] F. H. Gandoman, A. Ahmadi, A. M. Sharaf, P. Siano, J. Pou, B. Hredzak, V. G. Agelidis, "Review of FACTS technologies and applications for power quality in smart grids with renewable energy systems", Renewable and Sustainable Energy Reviews, Vol. 82, pp. 502-514, Feb. 2018.

[13] G. Shahgholian, A. Movahedi, "Power system stabiliser and flexible alternating current transmission systems controller coordinated design using adaptive velocity update relaxation particle swarm optimisation algorithm in multi-machine power system", IET Gen., Transm. and Distribution, Vol. 10, No. 8, pp. 1860-1868, May 2016. 
[14] O. Ziaee, F.F. Choobineh, "Optimal location-allocation of TCSC devices on a transmission network", IEEE Trans. on Power Systems, Vol. 32, No. 1, pp. 94-102, Jan. 2017.

[15] G. Shahgholian, H. Hamidpour, A. Movahedi, "Transient stability promotion by FACTS controller based on adaptive inertia weight particle swarm optimization method", Advances in Electrical and Electronic Engineering, Vol. 16, No. 1, pp. 57-70, March 2018.

[16] Z. Amini, A. Kargar, "Reduction of sub-synchronous resonances with D-FACTS devices using intelligent control", Journal of intelligent procedures in electrical technology, vol. 7, no. 26, pp. 3-14, Summer 2016.

[17] G. Shahgholian, Z. Azimi, "Analysis and design of a DSTATCOM based on sliding mode control strategy for improvement of voltage sag in distribution systems", Electronics, Vol. 5, No. 3, pp. 1-12, 2016.

[18] M. Mahdavian, G. Shahgholian, N. Rasti, "Modeling and damping controller design for static synchronous compensator", Proceeding of the IEEE/ECTICON, pp. 300-304, Pattaya, Chonburi, May 2009.

[19] G. Shahgholiyan, E. Haghjou, S. Abazari, "Improving the mitigation of voltage flicker by usage of fuzzy control in a distribution static synchronous compensator (DSTATCOM)", Majlesi Journal of Electrical Engineering, Vol. 3, No. 2, pp. 25-35, Summer 2009.

[20] G. Shahgholian, A. Movahedi, "Coordinated control of TCSC and SVC for system stability enhancement using ANFIS method", International Review on Modelling and Simulations, Vol. 4, No. 5, pp. 2367-2375, Oct. 2011.

[21] S. Jalali, G. Shahgholian, "Designing of power system stabilizer based on the root locus method with leadlag controller and comparing it with PI controller in multi-machine power system", Journal of Power Technologies, Vol. 98, No. 1, pp. 45-56, March 2018.

[22] O. Kahouli, M. Jebali, B. Alshammari, H.H. Abdallah, "PSS design for damping low-frequency oscillations in a multi-machine power system with penetration of renewable power generations", IET Renewable Power Generation, Vol. 13,No. 1, pp. 116-127, Jan. 2019.

[23] M. Zamani, G. Shahgholian, "Coordinated design of power system stabilizer and variable impedance devices to increase damping of inter-area modes using genetic algorithm", Iranian Journal of Electrical and Computer Engineering, Vol. 17, No. 4, pp. 271-278,Winter 2020.

[24] G. Shahgholian Ghfarokhi, M. Arezoomand, H. Mahmoodian, "Analysis and simulation of the singlemachine infinite-bus with power system stabilizer and parameters variation effects", Proceeding of the IEEE/ICIAS, Kuala Lumpur, Malaysia, pp. 167-171, Nov. 2007.

[25] G. Shahgholian, A. Etesami, "The effect of thyristor controlled series compensator on power system oscillation damping control", International Review of Electrical Engineering, Vol. 5, No. 2, pp. 18221830, Aug. 2011.

[26] A. Kazemi-Zahrani, M. Parastegari, "Designing PSS and SVC Parameters simultaneously through the improved quantum algorithm in the multi-machine power system", Journal of Intelligent Procedures in Electrical Technology, vol. 8, no. 31, pp. 68-75, Autumn 2017.

[27] M. Mahdavian, G. Shahgholian, P. Shafaghi, M. Azadeh, S. Farazpey, M. Janghorbani, "Power system oscillations improvement by using static var compensator", Proceeding of the IEEE/ECTICON, Thailand, June/July 2016.

[28] H. Ghaedi, G. Shahgholian, M. Hashemi. "Comparison of the effects of two flatness based control methods for STATCOM on improving stability in power systems including DFIG based wind farms", Iranian Electric Industry Journal of Quality and Productivity, Vol. 8, No. 15, pp. 81-90, 2019.

[29] G. Shahgholian, A. Rajabi, B. Karimi, M. Yousefi, "Design of power system stabilizer based on sliding mode control theory for multi- machine power system", Journal of Intelligent Procedures in Electrical Technology, vol. 1, no. 1, pp. 13-22, Winter 2010.

[30] M. Farahani, "Damping of subsynchronous oscillations in power system using static synchronous series compensator", IET Gen., Transm. and Distribution, Vol.6, No.6, pp.539-544, June 2012.

[31] S. Fazeli-Nejad, G. Shahgholian, M. Moazzami, "Artificial bee colony algorithm based approach for power system oscillation damping with PSS and STATCOM”, International Journal of Research Studies in Electrical and Electronics Engineering, vol. 5, no. 1, pp. 27-39, 2019.

[32] S. Ghasemi, E. Gholipoor, "Reactive power optimization in the presence of FACTS devices using evolutionary algorithms based on fuzzy logic", Journal of Intelligent Procedures in Electrical Technology, vol. 6, no. 23, pp. 45-54, Autumn 2015.

[33] J. Khazaie, M. Mokhtari, M. Khalilyan, D. Nazarpour, "Sub-synchronous resonance damping using distributed static series compensator (DSSC) enhanced with fuzzy logic controller", International Journal of Electrical Power and Energy Systems, Vol. 43, No. 1, pp. 80-89, Dec. 2012. 
[34] A. Hamidi, S. Golshannavaz, D. Nazarpour, "D-FACTS cooperation in renewable integrated microgrids: A linear multiobjective approach", IEEE Trans. on Sustainable Energy, vol. 10, no. 1, pp. 355-363, Jan. 2019.

[35] R. Pillay Carpanen, B.S. Rigby, "A contribution to modelling and analysis of SSSC-based power flow controls and their impact on SSR", Electric Power Systems Research, Vol. 88, pp. 98-111, July 2012.

[36] N. Ullah, M. Asghar Ali, R. Ahmad, A. Khattak, "Fractional order control of static series synchronous compensator with parametric uncertainty", IET Generation, Transmission and Distribution, vol. 11, no. 1, pp. 289-302, May 2017.

[37] S. Panda, S.C. Swain, A.K. Baliarsingh, "Real-code genetic algorithm for roboust coordinated design of excitation and SSSC-based controller", Journal of Electrical Engineering, Vol. 8, No. 4, 2008.

[38] H. Barati, R. Saki, S. Mortazavi, "Intelligent control of UPFC for enhancing transient stability on multimachine power systems", Journal of Intelligent Procedures in Electrical Technology, vol. 1, no. 1, pp. 312, Winter 2010.

[39] L. Wang, Q.S. Vo, "Power Flow Control and Stability Improvement of Connecting an Offshore Wind Farm to a One-Machine Infinite-Bus System Using a Static Synchronous Series Compensator", IEEE Trans. on Sustainable Energy, Vol. 4, No. 2, pp. 358-369, April 2013.

[40] R. Kumar, R. Singh, H. Ashfaq, "Stability enhancement of multi-machine power systems using Ant colony optimization-based static Synchronous Compensator", Computers and Electrical Engineering, Vol. 83, Article 106589, May 2020.

[41] R. Thirumalaivasan, M. Janaki, N. Prabhu, "Damping of SSR using subsynchronous current suppressor with SSSC", IEEE Trans. on Power Systems, Vol. 28, No. 1, pp. 64-74, Feb. 2013.

[42] S. Mahapatra, S. Panda, S.C. Swain, "A hybrid firefly algorithm and pattern search technique for SSSC based power oscillation damping controller design", Ain Shams Engineering Journal, Vol. 5, No. 4, pp. 1177-1188, Dec. 2014.

[43] J. Bhukya, V. Mahajan, "Optimization of damping controller for PSS and SSSC to improve stability of interconnected system with DFIG based wind farm", International Journal of Electrical Power and Energy Systems, Vol. 108, pp. 314-335, June 2019.

[44] V.S. Cheung, H.S. Chung, K. Wang, A.W. Lo, "Paralleling multiple static synchronous series compensators using daisy-chained transformers", IEEE Trans. on Power Electronics, vol. 29, no. 6, pp. 2764-2773, June 2014

[45] S.M. Abd Elazim, E.S. Ali, "Optimal SSSC design for damping power systems oscillations via gravitational search algorithm", International Journal of Electrical Power and Energy Systems, Vol. 82, pp. 161-168, Nov. 2016.

Citation: Majid Dehghani (2020)'Impacts of the SSSC on Damping Power System Oscillations, International Journal of Research Studies in Electrical and Electronics Engineering (IJRSEEE), 6(2), pp.716, DOI: http://dx.doi.org/10.20431/2454-9436.0602002

Copyright: () 2020 Majid Dehghani. This is an open-access article distributed under the terms of the Creative Commons Attribution License, which permits unrestricted use, distribution, and reproduction in any medium, provided the original author and source are credited 